\title{
Regulation of the Gene Encoding Glutathione Synthetase from the Fission Yeast
}

\author{
Su-Jung Kim, Youn Hee Shin, Kyunghoon Kim, Eun-Hee Park ${ }^{\dagger}$, Jae-Hoon Sa and Chang-Jin Lim* \\ Division of Life Sciences, Kangwon National University, Chuncheon 200-701, Korea \\ ${ }^{\dagger}$ College of Pharmacy, Sookmyung Womens University, Seoul 140-742, Korea \\ ${ }^{\ddagger}$ Department of Food and Drug Analysis, Kangwon Research Institute of Health and Environment, Chuncheon 200-093, Korea
}

Received 9 November 2002, Accepted 18 December 2002

\begin{abstract}
The fission yeast cells that contained the cloned glutathione synthetase (GS) gene showed 1.4-fold higher glutathione (GSH) content and 1.9-fold higher GS activity than the cells without the cloned GS gene. Interestingly, $\gamma$ glutamylcysteine synthetase activity increased 2.1-fold in the $S$. pombe cells that contained the cloned GS gene. The $S$. pombe cells that harbored the multicopy-number plasmid pRGS49 (containing the cloned GS gene) showed a higher level of survival on solid media with cadmium chloride $(1 \mathrm{mM})$ or mercuric chloride $(10 \mu \mathrm{M})$ than the cells that harbored the YEp357R vector. The 506 bp upstream sequence from the translational initiation point and $\mathrm{N}$-terminal 8 amino acid-coding region were fused into the promoterless $\beta$-galactosidase gene of the shuttle vector YEp367R to generate the fusion plasmid pUGS39. Synthesis of $\beta$-galactosidase from the fusion plasmid pUGS39 was significantly enhanced by cadmium chloride and NO-generating S-nitroso-N-acetylpenicillamine (SNAP) and sodium nitroprusside (SN). It was also induced by L-buthionine-(S,R)-sulfoximine, a specific inhibitor of $\boldsymbol{\gamma}$-glutamylcysteine synthetase (GCS). We also found that the expression of the $S$. pombe GS gene is regulated by the Atf1-Spc1-Wis1 signal pathway.
\end{abstract}

Keywords: Fission yeast, Glutathione synthetase, Nitrosative stress, Regulation, Schizosaccharomyces pombe, Transcription

\section{Introduction}

The tripeptide glutathione ( $\gamma$-L-glutamyl-L-cysteinyl-glycine, GSH), widely distributed in most living cells, is a principal

*To whom correspondence should be addressed.

Tel: 82-33-250-8514; Fax: 82-33-242-0459

E-mail: cjlim@kangwon.ac.kr antioxidant and a low-molecular-weight non-proteinous thiol compound. GSH plays an important role in maintaining the intracellular thiol redox state and protecting the cells against oxidative damage, xenobiotic organic chemicals, radiation, and heavy metals (Meister et al., 1989). GSH is an important electron donor for several enzymes that have a reducing step in their catalytic site, such as ribonucleotide reductase and glutathione peroxidase (Holmgren, 1976). In addition, it is involved in protein and DNA synthesis, maintenance of membrane integrity, and regulation of enzyme activities (Meister et al., 1989). Depletion of cellular GSH underlies tissue damage that is caused by a variety of metals and other thiol-directed chemicals (Reed, 1990). Altered glutathione homeostasis, in association with increased oxidative stress, has been implicated in the pathogenesis of many diseases, such as Alzheimer's disease and Parkinson's disease (Reid and Jahoor, 2001). Therefore, the regulation of de novo glutathione biosynthesis is likely to play a crucial role.

GSH is synthesized in the cytosol via two ATP-requiring enzymatic steps: the formation of $\gamma$-glutamylcysteine from Lglutamate and L-cysteine, and the formation of GSH from $\gamma$ glutamylcysteine and glycine. The first step is catalyzed by $\gamma$ glutamylcysteine synthetase (EC 6.3.2.2, GCS), whereas the second step is catalyzed by glutathione synthetase (EC 6.3.2.3, GS). The first step of GSH biosynthesis is generally regarded as a rate-limiting one and regulated by feed-back competitive inhibition by GSH and the availability of Lcysteine (DeLeve et al., 1991). GCS consists of a catalytic heavy subunit and a regulatory light subunit, which are encoded by different genes (Huang et al., 1993). The regulation on the expression of GCS genes has been relatively well documented. GCS subunits are up-regulated transcriptionally by $\alpha$-naphthoflavone (Morinova et al., 1998), a commonly used hepatocarcinogen thioacetamide (Lu et al., 1999), cadmium (Dormer et al., 2000; Shukla et al., 2000a; Shukla et al., 2000b), tumor necrosis factor (Morales et al., 1997), butylated hydroxytoluene (Tu et al., 1998), 
tertiary-butyl hydroperoxide (Stover et al., 2000), and nitric oxide (Moellering et al., 1998).

Only a few findings have been reported on the gene expressions that encode GS that catalyzes the final step of GSH biosynthesis. Mouse GS is induced by 1,10phenanthroline, a typical metal chelating reagent, although its induction is not sufficient to cause apoptosis (Sun, 1997). However, the physiological consequence of the 1,10phenanthroline-induced GS expression remains to be elucidated. In the yeast Saccharomyces cerevisiae, the expression of the GS gene is increased by heat-shock stress in a Yap1p-dependent fashion, and consequently the intracellular GSH content is increased (Sugiyama et al., 2000a). The increased synthesis of GSH in $S$. cerevisiae protects the mitochondrial DNA from oxidative damage that may lead to cell death (Sugiyama et al., 2000b). The treatment of hepatocytes or rats with diethyl maleate, buthionine sulfoximine, tert-butylhydroquinone, or thioacetamide, which increases the expression of GCS subunits, then increases the GS expression, which accordingly increases the GSH synthesis capacity (Huang et al., 2000). In this study, we investigated the regulation of the GS gene from the fission yeast Schizosaccharomyces pombe.

\section{Materials and methods}

Chemicals Unless stated otherwise, all of the biochemical reagents that were used in this study were purchased from Sigma Chemical Co (St. Louis, USA). Restriction enzymes, T4 DNA ligase and RNase A, were obtained from Roche Molecular Biochemicals (Mannheim, Germany). Seakem LE agarose was from Bioproducts (Hercules, USA). Agar, tryptone, and yeast extract were from United States Biochemicals (Cleveland, USA). PCR primers were ordered from the TaKaRa Shuzo Co. (Shiga, Japan).

Measurement of total GSH Total GSH content was determined by absorbance at $412 \mathrm{~nm}$ (Tietze, 1969) using oxidized GSH (GSSG) as the standard. In a final volume of $0.5 \mathrm{ml}$, the reaction mixture contained $100 \mathrm{mM}$ phosphate buffer (pH 7.0)-1 mM EDTA, $0.24 \mathrm{mM}$ NADPH, $0.0756 \mathrm{mM}$ 5,5-dithio-bis(2-nitrobenzoic acid), and 0.06 units glutathione reductase. Then $100 \mu 1$ of the appropriate standard or $100 \mu \mathrm{l}$ of the crude extract was added to each of the cuvettes. The absorbances, obtained from known concentrations of GSH, were used to construct a standard curve.

Enzymatic assays The $\gamma$-glutamylcysteine synthetase (GCS) activity was determined as previously described (Alton, 1985a). Enzyme activity was determined at $37^{\circ} \mathrm{C}$ in reaction mixtures of $1.0 \mathrm{ml}$ that contained $0.1 \mathrm{M}$ Tris- $\mathrm{HCl}$ buffer $(\mathrm{pH} 8.2), 150 \mathrm{mM}$ $\mathrm{KCl}, 5 \mathrm{mM}$ ATP, $2 \mathrm{mM}$ phosphoenolpyruvate, $10 \mathrm{mM}$ L-glutamate, $10 \mathrm{mM}$ L- $\alpha$-aminobutyrate, $20 \mathrm{mM} \mathrm{MgCl}_{2}, 2 \mathrm{mM}$ EDTA, $0.2 \mathrm{mM}$ $\mathrm{NADH}, 17 \mu \mathrm{g}$ of pyruvate kinase, and $17 \mu \mathrm{g}$ of lactate dehydrogenase. The reaction was initiated by the addition of an extract. The absorbance at $340 \mathrm{~nm}$ was monitored.
Glutathione synthetase (GS) activity was determined by measuring the formation of $\mathrm{ADP}$ in reaction mixtures that contained the enzyme and its substrates (Alton, 1985b). The reaction mixture contained $100 \mathrm{mM}$ Tris- $\mathrm{HCl}$ buffer $(\mathrm{pH} 8.2$ at $37^{\circ} \mathrm{C}$ ), $50 \mathrm{mM}$ potassium chloride, $5 \mathrm{mM}$ L- $\gamma$-glutamyl-L- $\alpha$ aminobutyrate, $10 \mathrm{mM}$ ATP, $5 \mathrm{mM}$ glycine, $20 \mathrm{mM}$ magnesium chloride, $2 \mathrm{mM}$ EDTA, and extract in a final volume of $0.1 \mathrm{ml}$. The assay mixture was incubated for $2.5-30 \mathrm{~min}$ at $37^{\circ} \mathrm{C}$. To determine the amount of ADP, the reaction mixtures were treated with $0.02 \mathrm{ml}$ of $10 \%$ sulfosalicylic acid and $0.9 \mathrm{ml}$ of a solution that contained $0.5 \mathrm{mM}$ phosphoenolpyruvate, $0.2 \mathrm{mM} \mathrm{NADH}$, pyruvate kinase (1 unit), $40 \mathrm{mM}$ magnesium chloride, $50 \mathrm{mM}$ potassium chloride, and $250 \mathrm{mM}$ potassium phosphate buffer, $\mathrm{pH}$ 7.0. The amount of ADP that was formed was calculated from the change in absorbance at $340 \mathrm{~nm}$ that was observed after the addition of $0.1 \mathrm{ml}$ (1 unit) of lactate dehydrogenase.

The $\beta$-galactosidase activity in extracts was measured by the spectrophotometric method using $o$-nitrophenyl- $\beta$-D-galactoside as the substrate (Guarente, 1983). The protein contents in the extracts were measured by the method of Bradford (Bradford, 1976).

\section{Results and Discussion}

Cloning of the $S$. pombe GS gene The $S$. pombe GS gene was previously isolated from a genomic library, and its coding sequence was revised (Mutoh et al., 1991; Wang et al 1997). To understand the physiological roles and regulation of the GS gene, it was cloned and characterized from $S$. pombe. Based on the reported sequence in the GenBank database, the genomic DNA that encodes the $S$. pombe GS was cloned by PCR. The genomic DNA was amplified with two synthetic primers that contained the BamHI and EcoRI sites, respectively. The two primers were designed to amplify the $506 \mathrm{bp}$ upstream sequence of the GS coding region, which was used for the regulation study. The resultant plasmid pMGS9 harbors the 2,297 bp insert in the yeast centromeric vector $\mathrm{pRS316}$. To determine the nucleotide sequence, two subclones were constructed using the unique HindIII site within the insert of pMGS9. Plasmid pMGS19 contained the BamHI-HindIII fragment, whereas plasmid pMGS29 contained the HindIII-EcoRI fragment. The original clone and the two subclones were subjected to automatic sequencing in Bionex Inc., Korea. The nucleotide sequence of the $S$. pombe GS gene was submitted to the GenBank under the accession number AF448236. The determined sequence was identical to the reported sequence (Mutoh et al., 1991), except for 4 positions.

Construction of the GS-lacZ fusion To conveniently monitor the GS gene expression, the upstream region of the GS gene that was cloned in pMGS9 was fused into the promoterless $\beta$-galactosidase gene of the shuttle vector YEp367R. The $506 \mathrm{bp}$ upstream sequence, as well as the region that encodes $\mathrm{N}$-terminal 8 amino acid residues that are contained in pMGS9, were amplified with a set of synthetic 
Table 1. Total GSH content, GCS and GS activities in S. pombe cells harboring plasmid pRGS49 containing the cloned GS gene

\begin{tabular}{ccc}
\hline Items & YEp357R & pRGS49 \\
\hline Total GSH $^{\mathrm{a}}$ & $4.930 \pm 0.875(100)$ & $6.849 \pm 0.231(139)$ \\
GCS $^{\mathrm{b}}$ & $1.068 \pm 0.050(100)$ & $2.287 \pm 0.078(214)$ \\
GS $^{\mathrm{b}}$ & $0.068 \pm 0.001(100)$ & $0.127 \pm 0.009(186)$ \\
\hline
\end{tabular}

- Values represent mean \pm SD. Numbers in parentheses indicate relative values.

${ }^{\mathrm{a}}$ Glutathione content was represented as $\mu \mathrm{g} / \mathrm{mg}$ protein.

${ }^{\text {b}}$ Specific activities of glutathione-synthesizing enzymes (GCS and GS) were represented as $\Delta \mathrm{A}_{340} / \mathrm{min} / \mathrm{ng}$ protein.

primers by PCR. The amplified DNA contained the BamHI and HindIII restriction sites, which originated from the synthetic primers. The PCR product that was digested by BamHI and HindIII was ligated into the BamHI/HindIII site of the vector YEp367R to generate the fusion plasmid pUGS39. Cells of the E. coli strain MV1184 that harbored the fusion plasmid pUGS39 formed blue colonies on X-gal plates, which indicates the promoter of the cloned GS gene is functional in E. coli.

Expression The insert DNA that is contained in the plasmid pMGS9 was transferred into the multicopy vector YEp357R (Cho et al., 2001a) in order to generate the plasmid pRGS49. To examine whether the cloned $S$. pombe GS gene produces a functional GS, plasmid pRGS49 was introduced into the wildtype $S$. pombe KP1 cells. The yeast cells that harbor plasmid pRGS49 were grown up to a mid-exponential phase, and harvested. Cell extract was used to measure total GSH content (Cho et al., 2001b), GCS and GS activities. The cells that harbor plasmid pRGS49 gave rise to 1.9-fold higher GS activity than the cells with the YEp357R vector (Table 1). This definitely confirms that the cloned GS is functional in $S$. pombe cells. Accordingly, the yeast cells that contained the cloned GS gene showed 1.4-fold higher GSH content than the cells with the vector only (Table 1). The increase in the GSH content could be caused by the increased GS activity. Unexpectedly, GCS activity was also increased 2.1-fold in $S$. pombe cells that contained the cloned GS gene (Table 1). The GCS activity may have been increased due to the decreased level of its reaction product, $\gamma$-glutamylcysteine, since enhanced GS activity excessively consumes it. However, a precise explanation requires further approaches. Taken together, enhanced GS activity in $S$. pombe cells has an influence on not only the GSH content, but also the GCS activity.

Yeast growth against heavy metal stresses and menadione Endogenous GSH concentrations can alter cellular responses to oxidative stress. Therefore, the increase in GSH has been proposed as a potential mechanism for enhancing the antioxidant defenses of the cells (Moellering et
Table 2. Survival of the $S$. pombe cells harboring plasmid pRGS49 against heavy metal stresses and menadione

\begin{tabular}{lcc}
\hline \multicolumn{1}{c}{ Conditions } & YEp357R & pRGS49 \\
\hline None & + & + \\
Cadmium chloride $(1 \mathrm{mM})$ & - & + \\
Mercuric chloride $(10 \mu \mathrm{M})$ & - & + \\
Cadmium chloride $(1 \mathrm{mM})+\mathrm{GSH}(20 \mathrm{mM})$ & + & + \\
Mercuric chloride $(10 \mu \mathrm{M})+\mathrm{GSH}(20 \mathrm{mM})$ & + & + \\
Menadione $(50 \mu \mathrm{M}, 100 \mu \mathrm{M})$ & - & + \\
\hline
\end{tabular}

The $S$. pombe cells harboring pRGS49 or YEp357R were streaked on minimal plates containing appropriate agents. +, growth; -, no growth.

$a l ., 1998)$. Since the $S$. pombe cells that harbor the cloned GS gene contains higher amounts of GSH, they would be more resistant to heavy metal stresses. To test this possibility, the $S$. pombe cells that harbor YEp357R or pRGS49 were streaked on minimal plates that contained cadmium chloride $(1 \mathrm{mM})$ or mercuric chloride $(10 \mu \mathrm{M})$. The yeast cells that contained the cloned GS gene were able to grow on heavy metal-containing plates, whereas the cells containing the vector only were not (Table 2). On the other hand, the addition of $20 \mathrm{mM} \mathrm{GSH}$ restored the growth of the control cells on the plates with heavy metals (Table 2). These facts suggest that the increased resistance to heavy metals of the yeast cells that contained the cloned GS gene may be directly linked with the increase in GSH content. The $S$. pombe GS gene was previously found to encode a bifunctional enzyme that is able to catalyze both the synthesis of GSH and the synthesis of phytochelatins, cadmium-binding peptides (Al-Lahham et al., 1999). Therefore, the increased resistance of the yeast cells that harbor the cloned GS gene against heavy metals could be due to the increased biosynthesis of phytochelatins. The yeast cells that contained the cloned GS gene could grow on superoxidegenerating menadione $(50 \mu \mathrm{M}, 100 \mu \mathrm{M})$, whereas the cells containing the vector only could not (Table 2). In $S$. cerevisiae, $\gamma$-glutamylcysteine was reported to be at least as good as GSH in protecting the yeast cells against an oxidant challenge (Grant et al., 1997).

Regulation Exponentially-grown $S$. pombe cells that contained the fusion plasmid pUGS39 were split and treated with two NO-generating agents sodium nitroprusside ( $\mathrm{SN}$, $3.0 \mathrm{mM}$ ) and S-nitroso-N-acetylpenicillamine (SNAP, $0.5 \mathrm{mM}$ ) (Fig. 1). The yeast cells were harvested at several time intervals after the treatment, and the $\beta$-galactosidase activity and protein content in the cell extract were analyzed. $\mathrm{SN}(3.0 \mathrm{mM})$ strongly enhanced the synthesis of $\beta$ galactosidase from the fusion plasmid pUGS39 in the $S$. pombe cells (Fig. 1A). At $9 \mathrm{~h}$ after the treatment, the $\beta$ galactosidase activity was elevated up to about 2.7-fold. SNAP $(0.5 \mathrm{mM})$ also enhanced the synthesis of $\beta$ galactosidase from the fusion plasmid pUGS39 in the $S$. pombe cells (Fig. 1B). At $6 \mathrm{~h}$ after the treatment, the $\beta$ - 

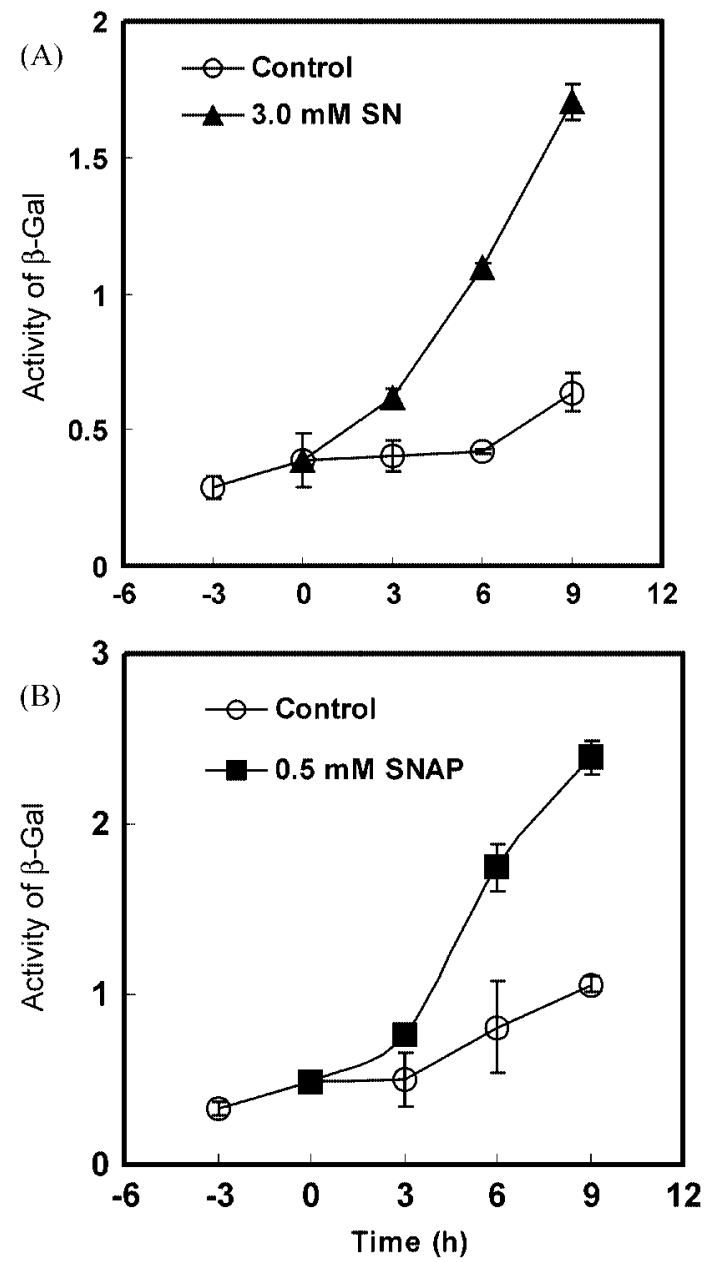

Fig. 1. Effect of NO-generating sodium nitroprusside (A) (SN $3.0 \mathrm{mM}$ ) and S-nitroso-N-acetylpenicillamine (B) (SNAP, $0 .$. $\mathrm{mM}$ ) on the synthesis of $\beta$-galactosidase from the fusion plasmic pUGS39 in $S$. pombe cells. The yeast cells that harbored the fusion plasmid were grown in a minimal medium, and split a the early exponential phase. The $\beta$-galactosidase activity was determined at $25^{\circ} \mathrm{C}$ by the spectrophotometric assay using ONPC as a substrate. Its specific activity was expressed in $\Delta \mathrm{A}_{42} / \mathrm{min} /$ mg protein.

galactosidase went up about 2.2-fold. In this study, both of the two tested NO-generating agents were able to enhance the $S$. pombe GS gene expression. The NO donors, SNAP and DetaNONOate, were previously reported to increase the total glutathione level in the primary cultures of the rat aortic cells (Moellering et al., 1998). Increased intracellular GSH by the NO donors resulted in the enhanced expression of GCS (Moellering et al., 1998). Similar results were obtained using HepG2 cells that were treated with SN (Galloway et al., 1999). However, the effect of NO donors on the GS gene expressions has never been examined.

L-Buthionine-(S,R)-sulfoximine (BSO) is known as a specific inhibitor of GCS. It is widely used as a tool for elucidating glutathione metabolism in vivo and as a

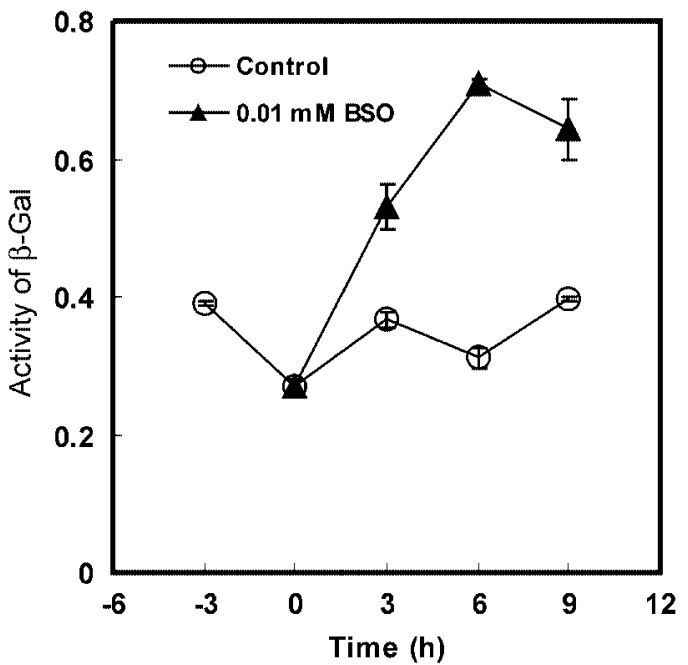

Fig. 2. Effect of L-buthionine-(S,R)-sulfoximine (BSO, 10 $\mu \mathrm{M})$ on the synthesis of $\beta$-galactosidase from the fusion plasmic pUGS39 in $S$. pombe cells. Experiments were performed as described in the legend of Fig. 1.

pharmacological agent for reversing glutathione-based resistance to chemotherapy and radiation therapy in certain cancers (Misra et al., 1998). BSO reportedly increases the expression of both of the GCS subunits in cultured-rat hepatocytes (Cai et al., 1997). BSO $(10 \mu \mathrm{M})$ significantly enhanced the synthesis of $\beta$-galactosidase from the fusion plasmid pUGS39 (Fig. 2). At $6 \mathrm{~h}$ after the treatment, the activity went up about 2.2-fold. BSO $(1 \mathrm{mM})$ increased the GS gene expression in the human normal liver cell line Chang cells (Huang et al., 2000). The induction effect of BSO on the expression of the $S$. pombe GS gene was obtained at a much lower concentration. Thioacetamide $(6.66 \mathrm{mM})$ increased the GS gene expression in Chang cells (Huang et al., 2000). However, its effect $(0.1 \mathrm{mM}, 0.5 \mathrm{mM})$ was not detected on the expression of the $S$. pombe GS gene (data not shown). Superoxide-generating menadione $(0.1 \mathrm{mM}, 0.2 \mathrm{mM})$ was able to induce the expression of the $S$. pombe GS gene (data not shown). Collectively, the expression of the $S$. pombe GS gene is regulated by stresses.

Atf1-dependence In response to oxidant stresses, eukaryotic cells induce gene expressions that are required for the detoxification of oxidants. There are two known stresssignaling pathways in S. pombe, the Wis1-Spc1-Atf1 pathway and Pap1 pathway (Nguyen et al., 2000). Induction of the $S$. pombe catalase gene expression upon oxidative stress is mediated by Pap1, a bZIP transcription factor that is homologous to human c-Jun and $S$. cerevisiae Yaplp, independent of the Spc1 stress-activated protein kinase (Nguyen et al., 2000). To understand the regulatory mechanism of the $S$. pombe GS gene, we used mutant strains. Figure 3A shows the GSH contents in three different $S$. pombe strains. The GSH content in the TP108-3C strains (Pap1- 

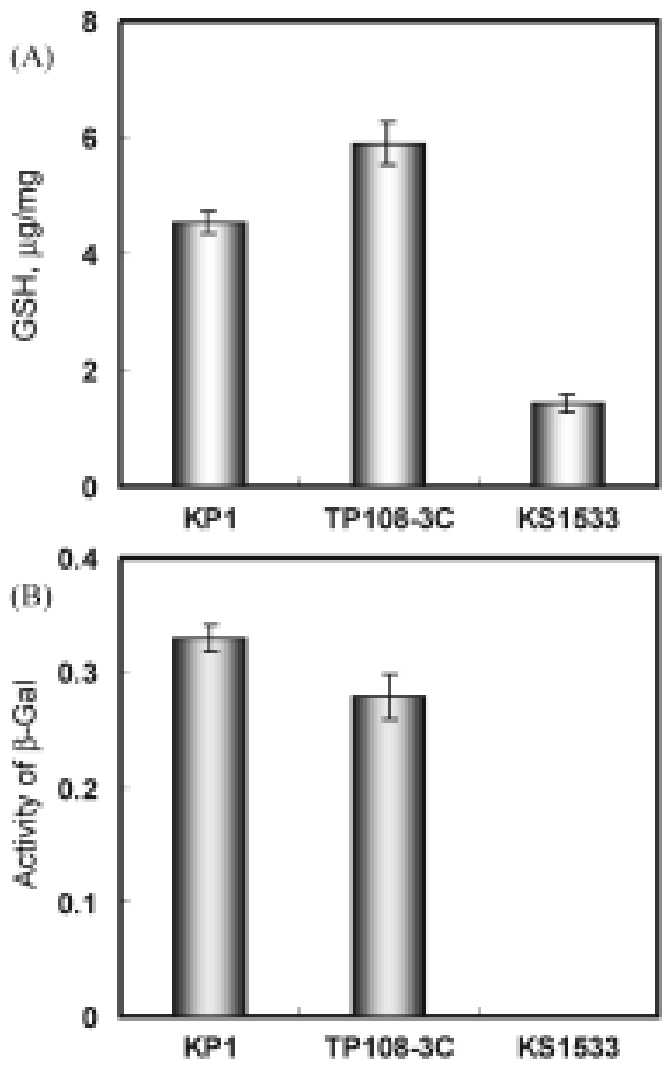

Fig. 3. GSH contents (A) and the synthesis of $\beta$-galactosidase (B) from the fusion plasmid pUGS39 in the $S$. pombe KP1 (wild-type), TP108-3C (papl::ura4 $4^{+}$, and KS1533 (spc1::ura4 atfl::ura $4^{+}$) cells. For the measurement of total GSH, the yeas cells without the fusion plasmid were harvested at the mid exponential phase. For the comparison of $\beta$-galactosidase synthesis, the three different yeast cells that harbored the fusior plasmid pUGS39 were also harvested at the mid-exponentia phase. GSH content was expressed as $\mu \mathrm{g} / \mathrm{mg}$ protein, and $\beta$ galactosidase specific activity was represented as $\Delta \mathrm{A}_{420} / \mathrm{min} / \mathrm{mg}$ protein.

negative mutant) was comparable to that in the wild-type strain KP1 (Fig. 3A). However, the GSH content in KS1533 (Spc1- and Atf1-negative mutant) was much lower than those in the KP1 and TP108-3C strains (Fig. 3A). These suggest that the GSH synthesis would be dependent on the Wis1Spc1-Atfl pathway. Therefore, the effect of Atfl on the synthesis of $\beta$-galactosidase from the fusion plasmid pUGS39 was examined (Fig. 3B). The synthesis of $\beta$-galactosidase from the fusion plasmid in TP108-3C appeared to be similar to that in the KP1 strain (Fig. 3B). On the contrary, the synthesis of $\beta$-galactosidase from the fusion plasmid in the KS1533 strain was completely repressed (Fig. 3B). Its synthesis could not be induced in the KS1533 strain by SN $(3.0 \mathrm{mM})$, SNAP $(0.5 \mathrm{mM})$, or BSO $(10 \mu \mathrm{M})$ (data not shown). However, the synthesis of $\beta$-galactosidase from the fusion plasmid was normally enhanced in the TP108-3C strain by those agents (Fig. 4). Conclusively, the induction of the $S$.

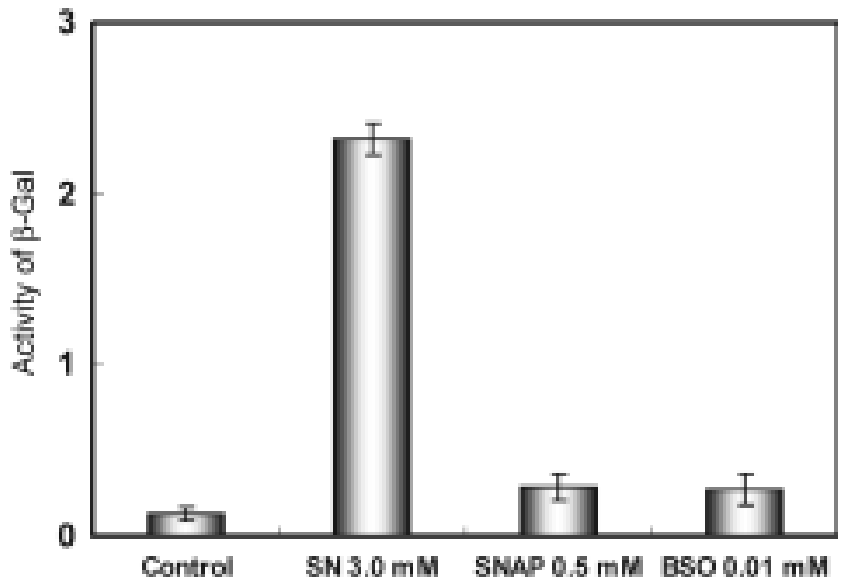

Fig. 4. Enhancement of $\beta$-galactosidase biosynthesis from the fusion plasmid pUGS39 in S. pombe TP108-3C (pap1::ura4 $4^{+}$) cells. At $6 \mathrm{~h}$ after the treatments with sodium nitroprusside (SN $3.0 \mathrm{mM}$ ), S-adenosyl-N-acetylpenicillamine (SNAP, $0.5 \mathrm{mM}$ ), o buthionine-L-sulfoximine $(\mathrm{BSO}, 10 \mu \mathrm{M})$, the yeast cells were harvested for measuring $\beta$-galactosidase activity. $\beta$-Galactosidase specific activity was represented as $\Delta \mathrm{A}_{42} / \mathrm{min} / \mathrm{mg}$ protein.

pombe GS gene by nitrosative stresses and BSO is mediated by Atfl, but not by Pap1. In S. cerevisiae, the GS gene expression was regulated by Yap1p under oxidative stressinduced conditions (Sugiyama et al., 2000a). Our results propose that GS also plays a role in regulating GSH synthesis, in addition to GCS activity.

Acknowledgments This work was supported by a Korea Research Foundation Grant (KRF-2001-015-DP0383). We are grateful to Dr. K. Shiozaki for kindly donating the mutant strains of S. pombe.

\section{References}

Al-Lahham, A., Rohde, V., Heim, P., Leuchter, R., Veeck, J., Wunderlich, C., Wolf, K. and Zimmermann, M. (1999) Biosynthesis of phytochelatins in the fission yeast. Phytochelatin synthesis: a second role for the glutathione synthetase gene of Schizosaccharomyces pombe. Yeast 30, 385395.

Alton, M. (1985a) $\gamma$-Glutamylcysteine synthetase from erythrocytes. Methods Enzymol. 113, 390-392.

Alton, M. (1985b) Glutathione synthetase from rat kidney. Methods Enzymol. 113, 393-399.

Bradford, M. M. (1976) A rapid and sensitive method for the quantitation of microgram quantities of protein utilizing the principle of protein dye binding. Anal. Biochem. 72, 248-254.

Cai, J., Huang, Z. Z. and Lu, S. C. (1997) Differential regulation of gamma-glutamylcysteine synthetase heavy and light subunit gene expression. Biochem. J. 326, 167-172.

Cho, Y. W., Sa, J. H., Park, E. H. and Lim, C. J. (2001a) Expression of schizosaccharomyces pombe Thioltransferase and Thioredoxin genes under limited growth conditions J. Biochem. 
Mol. Biol. 34, 395-401.

Cho, Y. W., Park, E. H., Ahn, K. S., Kim, D and Lim, C. J. (2001b) Growth-dependent variations in antioxidant and redox enzyme activities of schizosaccharomyces pombe. J. Biochem. Mol. Biol. 34, 278-283.

DeLeve, L. and Kaplowitz, N. (1991) Glutathione metabolism and its role in hepatotoxicity. Pharmac. Ther. 52, 287-305.

Dormer, U. H., Westwater, J., McLaren, N. F., Kent, N, A., Mellor, J. and Jamieson, D. J. (2000) Cadmium-inducible expression of the yeast $G S H 1$ gene requires a functional sulfuramino acid regulatory network. J. Biol. Chem. 275, 3261132616.

Galloway, D. C., Blake, D. G. and McLellan, L. I. (1999) Regulation of $\gamma$-glutamylcysteine synthetase regulatory subunit (GLCLR) gene expression: identification of the major transcriptional start site in HT29 cells. Biochim. Biophys. Acta 1446, 47-56.

Grant, C. M., Maclver, F. H. and Dawes, I. W. (1997) Glutathione synthetase is dispensable for growth under both normal and oxidative stress condition in the yeast Saccharomyces cerevisiae due to an accumulation of the peptide gamma-glutamylcysteine. Mol. Biol. Cell 8, 1699-1707.

Guarente, L. (1983) Yeast promoters and LacZ fusion designed to study the expression of cloned genes in yeast. Methods Enzymol. 101, 181-191.

Holmgren, A. (1976) Hydrogen donor system for Escherichia coli ribonucleoside-diphosphate reductase dependent upon glutathione. Proc. Natl. Acad. Sci. USA 73, 2275-2279.

Huang, C., Chang, L., Anderson, M. E. and Meister, A. (1993) Catalytic and regulatory properties of the heavy subunit of rat kidney $\gamma$-glutamylcysteine synthetase. J. Biol. Chem. 268, 19675-19680.

Huang, S.-S., Yang, H., Chen, C., Zeng, Z. and Lu, S. C. (2000) Inducers of $\gamma$-glutamylcysteine synthetase and their effects on glutathione synthetase expression. Biochim. Biophys. Acta 1493, 48-55.

Lu, S. C., Huang, Z.-Z., Yang, H. and Tsukamoto, H. (1999) Effect of thioacetamide on the hepatic expression of $\gamma$ glutamylcysteine synthetase subunits in the rat. Toxicol. Appl. Pharmacol. 159, 161-168.

Meister, A. (1989) Metabolism and function of glutathione; in Glutathione: chemical, biochemical, and medical aspects, Dolphin, D., Poulson, R. and Auramovic, R. (eds.), pp. 367474, John Wiley and Sons, New York, USA.

Misra, I. and Griffith, O. W. (1998) Expression and purification of human $\gamma$-glutamylcysteine synthetase. Protein Exp. Purif. 13, 268-276.

Moellering, D., McAndrew, J., Patel, R. P., Cornwell, T., Lincoln, T., Cao, X., Messina, J. L., Forman, H. J., Jo, H. and DarleyUsmar, V. M. (1998) Nitric oxide-dependent induction of glutathione synthesis through increased expression of $\gamma$ glutamylcysteine synthetase. Arch. Biochem. Biophys. 358, 7482.
Moinova, H. R. and Mulcahy, R. T. (1998) An electrophile responsive element (EpRE) regulates $\beta$-naphthoflavone induction of the human $\gamma$-glutamylcysteine synthetase regulatory subunit gene. J. Biol. Chem. 273, 14683-14689.

Morales, A., Garcia-Ruiz, C., Miranda, M., Mari, M., Colell, A., Ardite, E. and Fernandez-Checa, J. C. (1997) Tumor necrosis factor increases hepatocellular glutathione by transcriptional regulation of the heavy subunit chain of $\gamma$-glutamylcysteine synthetase. J. Biol. Chem. 272, 30371-30379.

Mutoh, N., Nakagawa, C. W., Ando, S., Tanabe, K. and Hayashi, Y. (1991) Cloning and sequencing of the gene encoding the large subunit of glutathione synthetase of Schizosaccharomyces pombe. Biochem. Biophys. Res. Commun. 181, 430-436.

Nguyen, A. N., Lee, A., Place, W. and Shiozaki, K. (2000) Multistep phosphorelay proteins transmit oxidative stress signals to fission yeast stress-activated protein kinase. Mol. Biol. Cell 11, 1169-1181.

Reed, D. J. (1990) Glutathione: toxicological implications. Annu. Rev. Pharmacol. Toxicol. 30, 603-631.

Reid, M. and Jahoor, F. (2001) Glutathione in disease. Curr. Opin. Clin. Nutr. Metab. Care 4, 65-71.

Shukla, G. S., Chiu, J.-F. and Hart, B. A. (2000a) Enhanced expression of pulmonary $\gamma$-glutamylcysteine synthetase heavy subunit in rats exposed to cadmium aerosols. Toxicol. Appl. Pharmacol. 163, 249-259.

Shukla, G. S., Chiu, J-F. and Hart, B. A. (2000b) Cadmiuminduced elevations in the gene expression of the regulatory subunit of $\gamma$-glutamylcysteine synthetase in rat lung and alveolar epithelial cells. Toxicol. 151, 45-54.

Stover, S. K., Gushansky, G. A., Salmen, J. J. and Gardiner, C. S. (2000) Regulation of $\gamma$-glutamate-cysteine ligase expression by oxidative stress in the mouse preimplantation embryo. Toxicol. Appl. Pharmacol. 168, 153-159.

Sugiyama, K., Izawa, S. and Inoue, Y. (2000a) The Yap1pdependent induction of glutathione synthesis in heat shock response of Saccharomyces cerevisiae. J. Biol. Chem. 275, 15535-15540.

Sugiyama, K., Kawamura, A., Izawa, S. and Inoue, Y. (2000b) Role of glutathione in heat shock-induced cell death of Saccharomyces cerevisiae. Biochem. J. 352, 71-78.

Sun, Y. (1997) Induction of glutathione synthetase by 1,10phenanthroline. FEBS Lett. 408, 16-20.

Tietze, F. (1969) Enzymic method for quantitative determination of nanogram amount of total GSH and GSSG. Anal. Biochem. 27, 502-522.

Tu, Z. and Anders, M. W. (1998) Up-regulation of glutamatecysteine ligase gene expression by butylated hydroxytoluene is mediated by transcription factor AP-1. Biochem. Biophys. Res. Commun. 244, 801-805.

Wang, C.-L. and Oliver, D. J. (1997) Glutathione synthetase: Similarities of the proteins from Schizosaccharomyces pombe and Arabidopsis thaliana. Biochem. J. 326, 563-566. 